\title{
Ridge Preservation done Immediately following Extraction using Bovine Bone Graft, Collagen Plug and Collagen Membrane
}

\author{
Dhruv Gupta, Gayatri Gundannavar, Dwarakanath Doraiswamy Chinni, Ramesh Vishwanath Alampalli
}

\begin{abstract}
Background and objectives: Socket augmentation at the time of extraction is an attempt to reduce crestal bone loss, encourage socket fill, minimize horizontal ridge resorption, and ultimately reduce or eliminate the need for further ridge augmentation. The aim of this study is to evaluate the efficacy of naturally derived bovine hydroxyapatite, resorbable collagen membrane and collagen plug in ridge preservation as compared to an unassisted naturally healing extraction site.
\end{abstract}

Methods: Twenty-two systemically healthy patients participated in the study. Seventeen completed the study and were included for analysis. One site in each patient was treated as control site and only received an atraumatic extraction procedure while the other site was subjected to a ridge preservation procedure following atraumatic extraction. Parameters, such as loss of ridge width, loss of ridge height were measured clinically, with the help of occlusal stents on pre- and postoperative models and radiographically with the help of AutoCAD software. These measurements were made at baseline as well as 6 months post-operative.

Results: The treatment modality resulted in significant reduction in the amount of loss of ridge width and loss of ridge height in the test sites when compared to the control sites. The mean loss of ridge width was found to be $1.68 \mathrm{~mm}$ at the control sites and $1.07 \mathrm{~mm}$ at the test sites. The mean loss of ridge height was found to be $2.43 \mathrm{~mm}$ at the control sites and $1.45 \mathrm{~mm}$ at the test sites. All these differences were found to be statistically significant.

Interpretation and conclusion: The results of this study suggest that a ridge preservation procedure carried out at the time of extraction is a reliable and predictable method to minimize the resorption of the alveolar bone that takes place postextraction and offers the patients a relatively easy, cost effective method that spares them the discomfort of further ridge augmentation procedures that might be necessary for an esthetic rehabilitation or implant placement.

Keywords: Socket, Bio-Oss, Socket preservation, Collagen plug, Ridge preservation.

How to cite this article: Gupta D, Gundannavar G, Chinni DD, Alampalli RV. Ridge Preservation done Immediately following Extraction using Bovine Bone Graft, Collagen Plug and Collagen Membrane. Int J Oral Implantol Clin Res 2012;3(1):8-16.

Source of support: Nil

Conflict of interest: None declared

\section{INTRODUCTION}

An excellent functional and esthetic restoration depends upon its placement in an optimal location that will achieve the restorative goals. In extraction cases with advanced bone loss as a result of periodontal disease, root or labial bone fracture, extensive carious or periapical lesions, a localized ridge deformity of varying severity occurs, probably due to elimination of the four walled socket in which the blood clot forms and is protected. ${ }^{1}$ Studies have demonstrated that the resorption of alveolar bone following extractions results in a narrowing and shortening of the residual ridge. ${ }^{2}$ The prosthetic rehabilitation in these cases becomes difficult because the ridge deformity requires a modification of the prosthetic design resulting in buccal/lingual and occlusal/ apical concavities that can affect both the reestablishment of function and esthetics while making it difficult to maintain oral hygiene. From a surgical standpoint, the height, the buccal-lingual position and dimensions of the alveolar ridge influence implant position. Since, ridge dimensions are so critical, it is important to recognize that postextraction ridge preservation is essential to ensure maintenance of ideal vertical and horizontal ridge dimensions and contours.

An average of 40 to $60 \%$ of original height and width is expected to be lost after tooth extraction, with the greatest loss happening within the first 2 years. ${ }^{3}$ The removal of a tooth begins a cascade of events within the socket that will completely heal with bone within 4 to 6 months. However, the final contour of the bone is reduced in width by $25 \%$. In addition, as the epithelium migrates over the socket, the intraseptal bone is lost and the bone slopes from the higher lingual aspect to the more apical facial cortical plate, which reduces the crestal height of bone. It is speculated that this is due in part to the constriction of the blood clot within the alveolus and the thin labial cortical plates remodeling in response to inadequate blood supply after the extraction. In addition, preexisting periodontal or endodontic disease or trauma from the extraction often destroy the labial bony plate and causes the immediate loss of width and height of bone, which may exceed $50 \%$ of the optimum volume. ${ }^{4}$ Research has demonstrated that the alveolar ridge at the maxillary anterior area can be reduced by $23 \%$ in the first 6 months after exodontia and an additional 11\% in the following 5 years. In the posterior mandible, resorption happens primarily in the buccal/labial direction, resulting in a lingual displacement of alveolar crest. ${ }^{5}$ The rate of reduction of residual alveolar ridges has shown to be greater 
in mandibular $(0.4 \mathrm{~mm} /$ year $)$ than in maxillary arches $(0.1 \mathrm{~mm} / \text { year })^{1}$

There are many techniques with an objective to reconstruct ridge deformities, these include autogenous soft tissues grafts; nonresorbable alloplastic materials and guided bone regeneration using membranes alone or in association with different graft materials. Although these procedures are available to esthetically reconstruct deficiencies in soft and hard tissues, they involve additional surgical intervention and have somewhat unpredictable results. ${ }^{2}$

Since, alveolar ridge resorption is an unavoidable sequel of tooth loss it would be prudent to preserve it at the time of extraction. Ridge preservation technique can prevent loss of both hard and soft tissues, reduce the number of surgical interventions, and provide optimum esthetics with greater predictability.

Ridge preservation is any procedure undertaken at the time of or following an extraction that is designed to minimize external resorption of the ridge and maximize bone formation within the socket. ${ }^{6}$ Some ridge preservation techniques are based on the principles of guided tissue and bone regeneration. Many procedures have been suggested including minimally traumatic tooth extraction, soft and hard tissue grafting, concomitant use of barrier membranes and immediate implant placement.

Hence, it was envisaged to take up a study comparing extraction sites where normal healing was allowed to take place with extraction sites where ridge preservation was done using a combination of bovine bone graft, collagen plug and a resorbable collagen membrane.

\section{METHODOLOGY}

A total of 22 patients visiting the Department of Periodontics, The Oxford Dental College, Bengaluru were recruited for this randomized controlled trial. The patients presented with at least two teeth indicated for extraction which are not adjacent to each other. Five patients were excluded from the study as they did not return after extraction of the first tooth or during the follow-up time period or needed further extractions adjacent to the sites initially included in the study.

The study protocol was approved by the Ethical Committee of The Oxford Dental College, Hospital and Research Centre. The study was carried out over a period of 1 year. The causes for extraction of the teeth may be root fractures, hopeless periodontal prognosis, endodontic treatment failures, advanced carious lesions. Patients having systemic diseases including metabolic bone disease, pregnancy, radiotherapy/chemotherapy, heavy smokers (more than 10 cigarettes per day), patients with a distinct periapical pathology which can be detected by a preoperative radiograph, patients undergoing complete extraction or needing extraction of most of their teeth were excluded from the study.

The 20 patients who fulfilled the above-mentioned criteria were allocated into two groups (test and control). The purpose of the study together with all the details was explained to the patients and informed consent was obtained. Initial periodontal therapy comprised of patient education and motivation, scaling followed by root planing under local anesthesia and oral hygiene instructions for optimum plaque control.

\section{Preoperative Procedure}

Preoperative casts and an occlusal stent were fabricated using self-cure acrylic resin. Over the extraction site, the model was trimmed to facilitate a reproducible vertical measurement from the mid-alveolar crest to the coronal part of the stent. The width of the alveolar ridge (buccolingual dimension) was measured at the extraction site on the cast as the distance between the most prominent sites buccally and lingually using a digital vernier caliper. The measurements were recorded at the time of extraction and 6 months postsurgery. The extraction on both sites was carried out at the same time whenever feasible, otherwise the procedures were carried out within a week of each other.

\section{Radiographic Examination}

Standardized intraoral periapical radiographs were taken from all the patients using long cone paralleling technique (Figs 1 to 6 ).

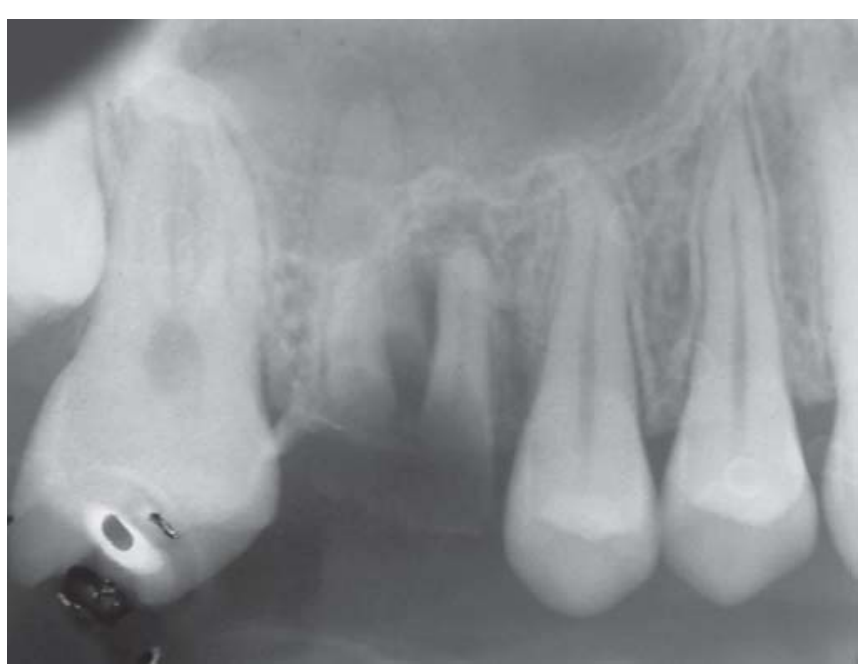

Fig. 1: Control site (16) preoperative 


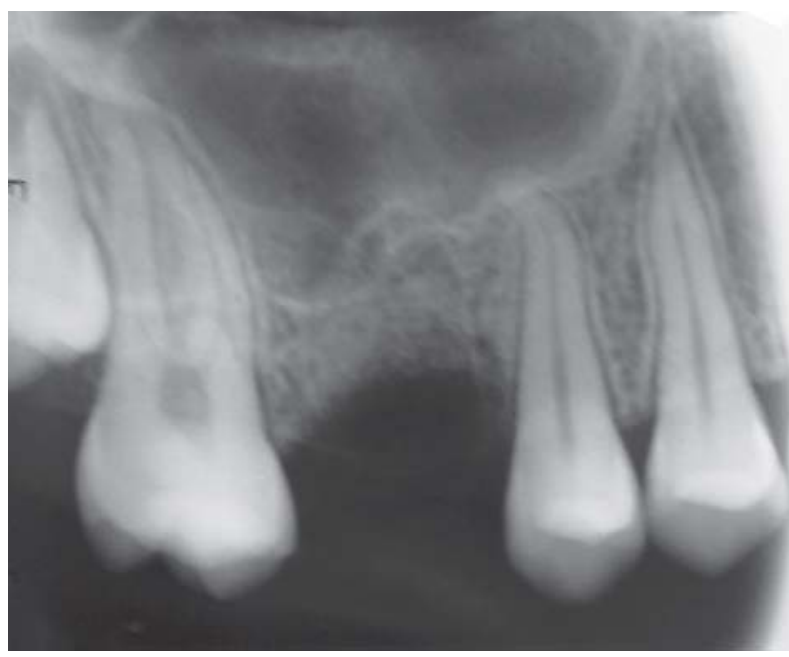

Fig. 2: Control site (16) at baseline

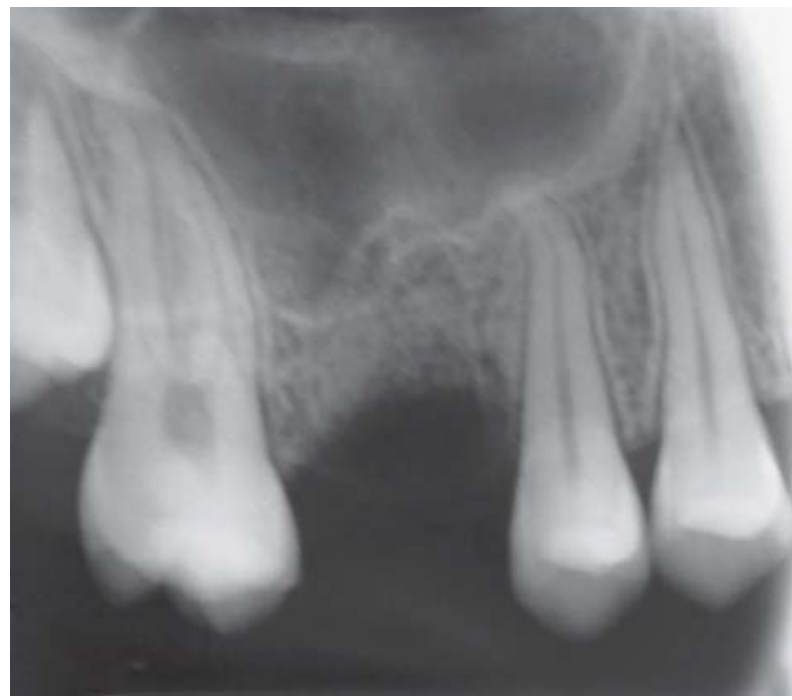

Fig. 3: Control site (16) at 6 months

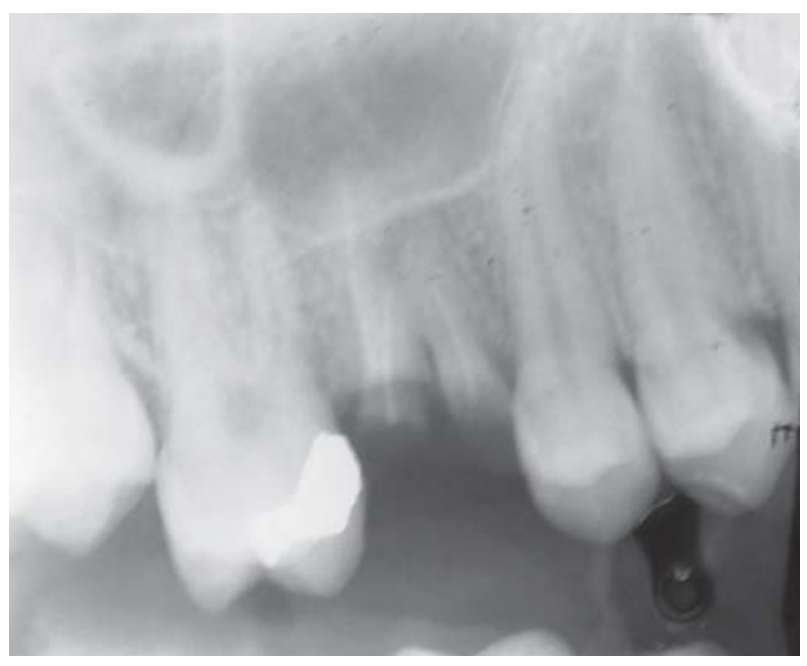

Fig. 4: Test site (26) preoperative

\section{Radiographic Measurements}

After initial therapy, standardized intraoral periapical radiographs using RINN XCP (Dentsply, USA) at baseline

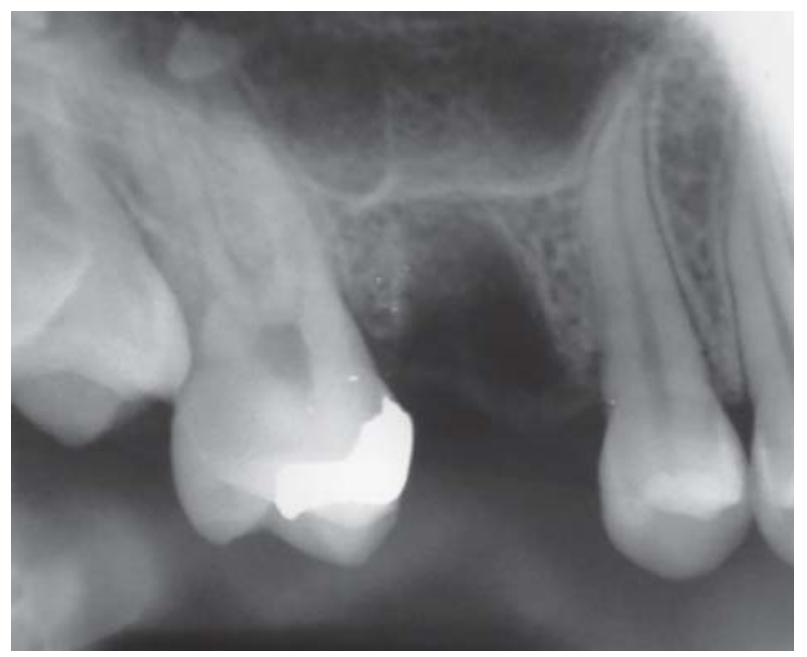

Fig. 5: Test site (26) baseline

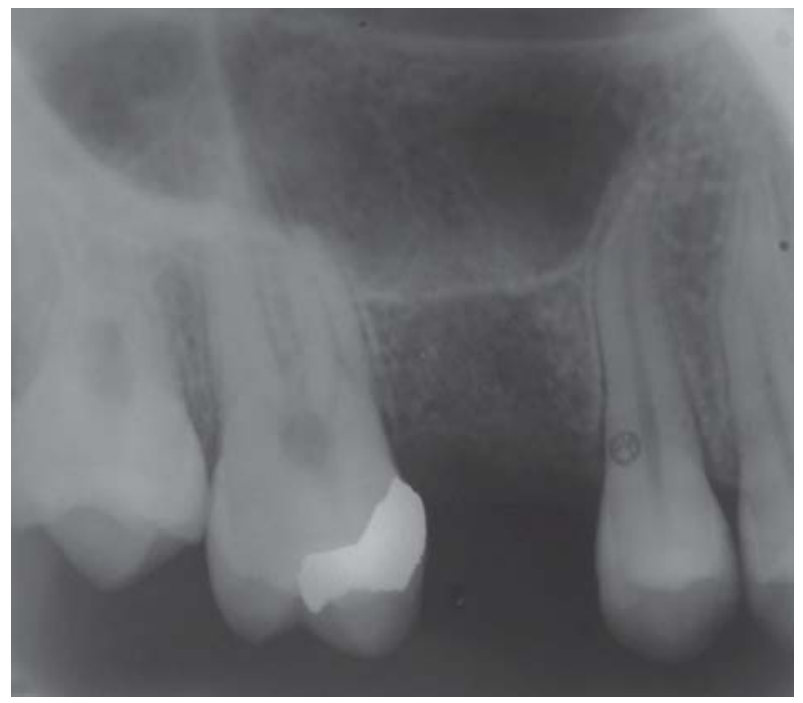

Fig. 6: Test site (26) at 6 months

and 6th month following surgery were taken. The following landmarks were identified on the radiographs:

- Cementoenamel junction (CEJ) of the teeth adjacent to the extraction site, if the CEJ was destroyed by restorative treatment, the margin of the restoration is taken as landmark

- Superficial most point of the alveolar crest (AC)

- The depth of the extraction socket.

The radiographic linear measurements were made with the help of standardized AutoCAD software at baseline and 6th month postsurgically.

\section{Surgical Procedure}

The surgical procedure was performed under local anesthesia of $2 \%$ lignocaine containing adrenaline at a concentration of 1:200,000. Standard surgical protocol was followed during the entire surgical procedure. Buccal and lingual (palatal) crevicular incisions were extended till one tooth on either side of the tooth to be extracted and full 
thickness mucoperiosteal flaps were elevated. Care was taken to preserve as much interproximal soft tissue as possible.

Periotomes were then applied to sever the subcrestal attachment apparatus. Additional elevation using a periosteal elevator was performed wherever required. Once sufficient mobility was achieved, the dental forceps were applied to remove the tooth.

After tooth removal, the socket was thoroughly curetted of all soft tissue debris. Bleeding was stimulated from the osseous base by scraping the walls of the socket with either curettes or rotary instruments. The bone graft material (BioOss $^{\mathrm{TM}}$ ) along with collagen plug (CollaPlug ${ }^{\mathrm{TM}}$ ) was placed down lightly and overfill was avoided. A resorbable collagen membrane (Perioguide ${ }^{\mathrm{TM}}$ ) was placed over the extraction site. An incision was made at the base of the flap to mobilize it and soft tissues were approximated to achieve optimal coverage. A cross-mattress suture was then used to secure the surgical site (Figs 7 to 17).

\section{Postoperative Care and Evaluation}

The patients were put on an antibiotic regime consisting of amoxicillin $500 \mathrm{mg}$ three times a day for 5 days along with

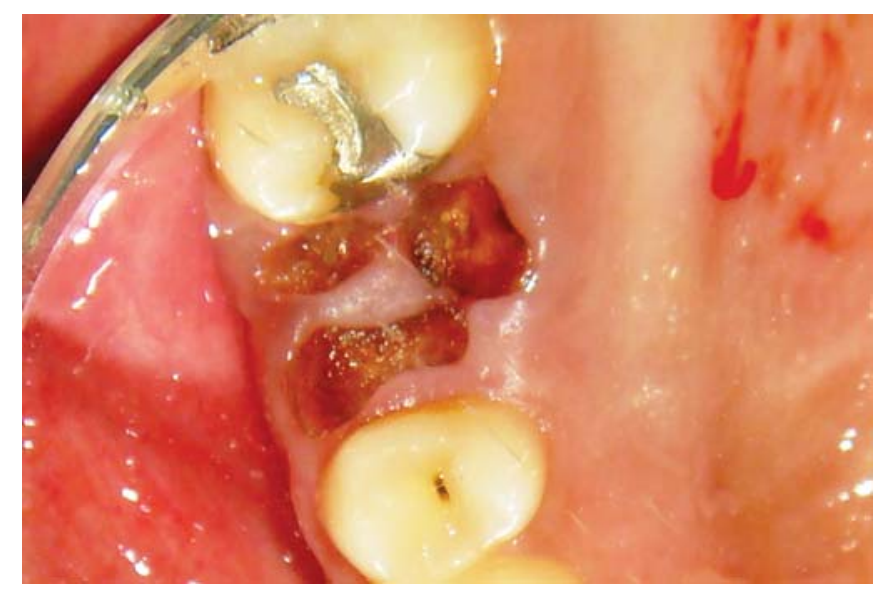

Fig. 7: Preoperative 16

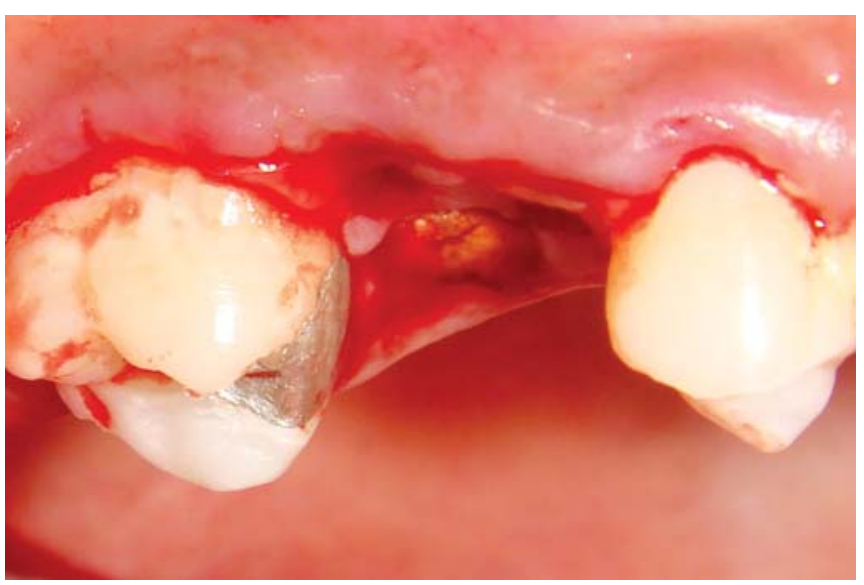

Fig. 8: Cervicular incisions placed

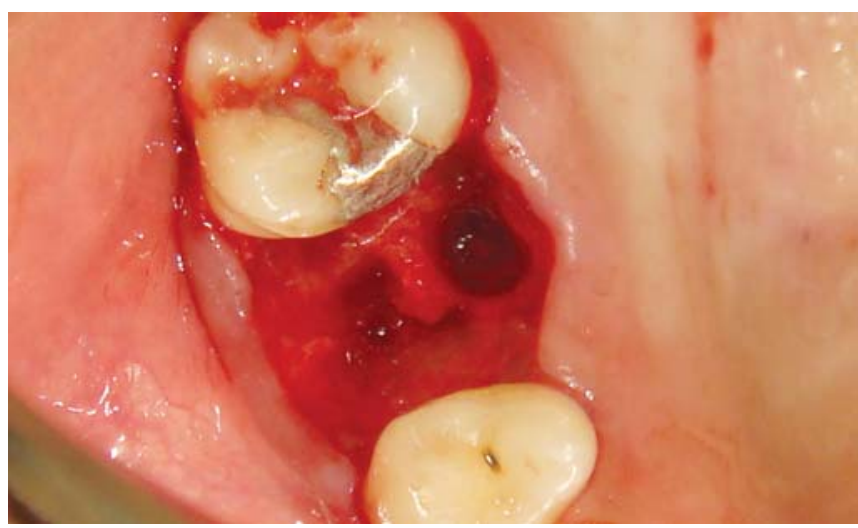

Fig. 9: Extraction socket

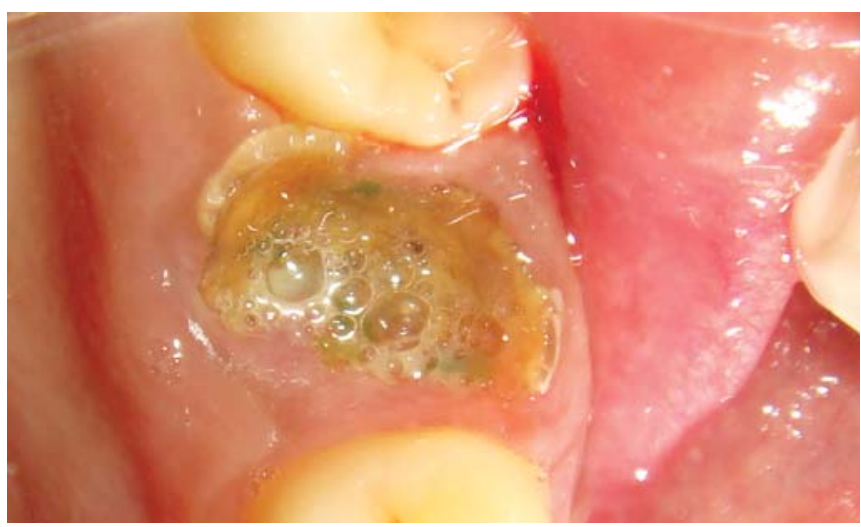

Fig. 10: Preoperative 26

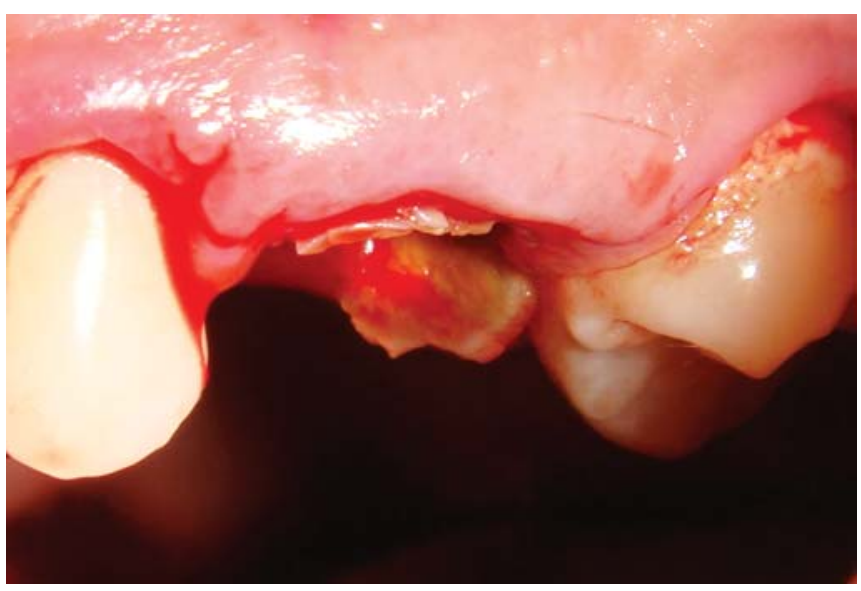

Fig. 11: Cervicular incisions

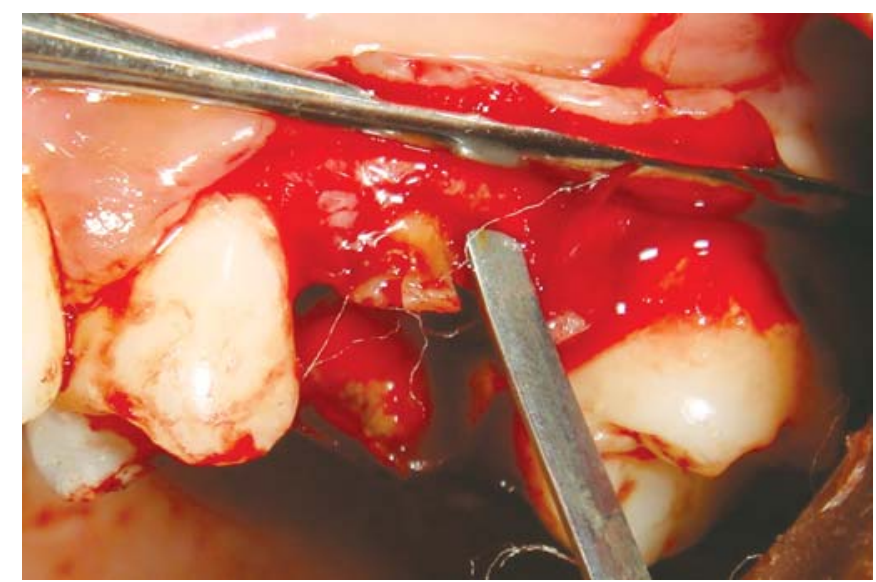

Fig. 12: Full thickness mucoperiosteal flap raised and periotomeapplied 


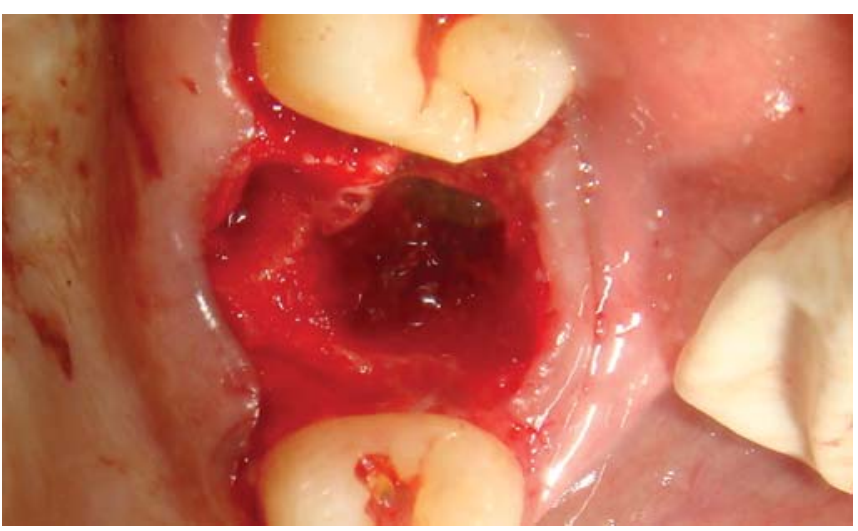

Fig. 13: Debrided extraction socket

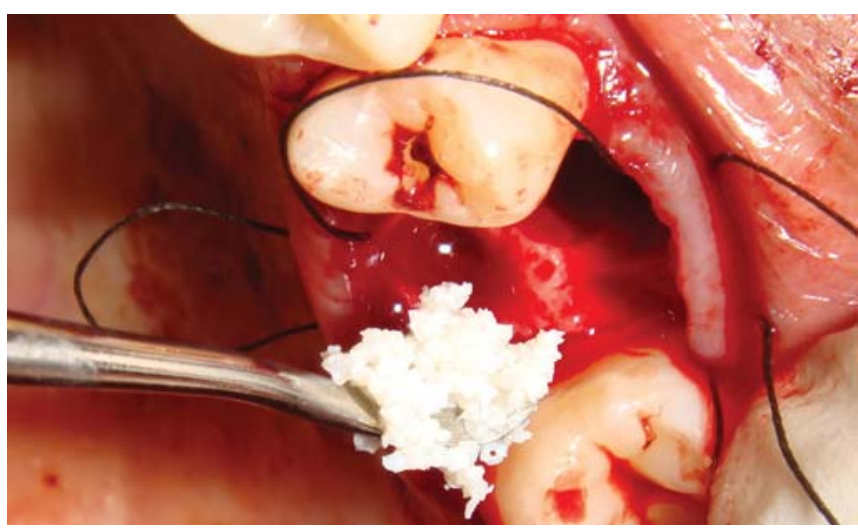

Fig. 14: BioOss $^{\mathrm{TM}}$ and Collaplug ${ }^{\mathrm{TM}}$

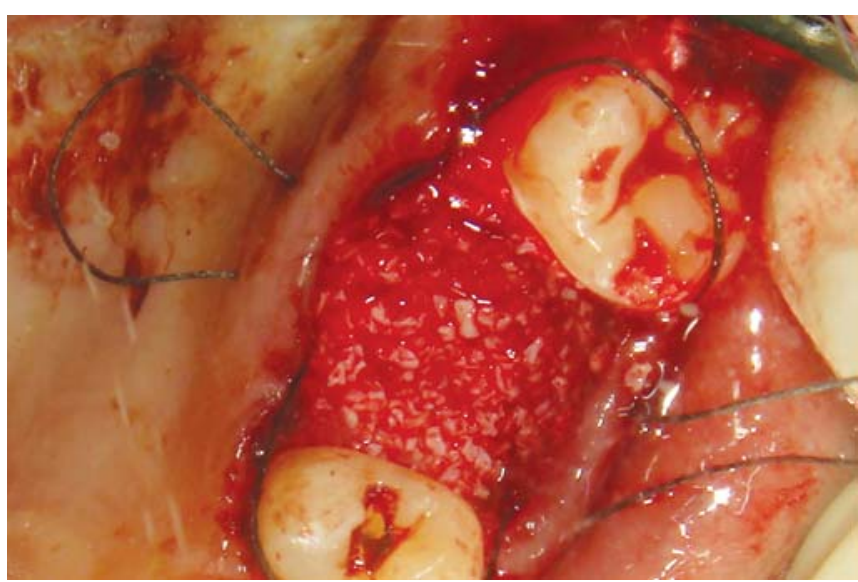

Fig. 15: BioOss ${ }^{\mathrm{TM}}$ and Collaplug ${ }^{\mathrm{TM}}$ placed in the socket

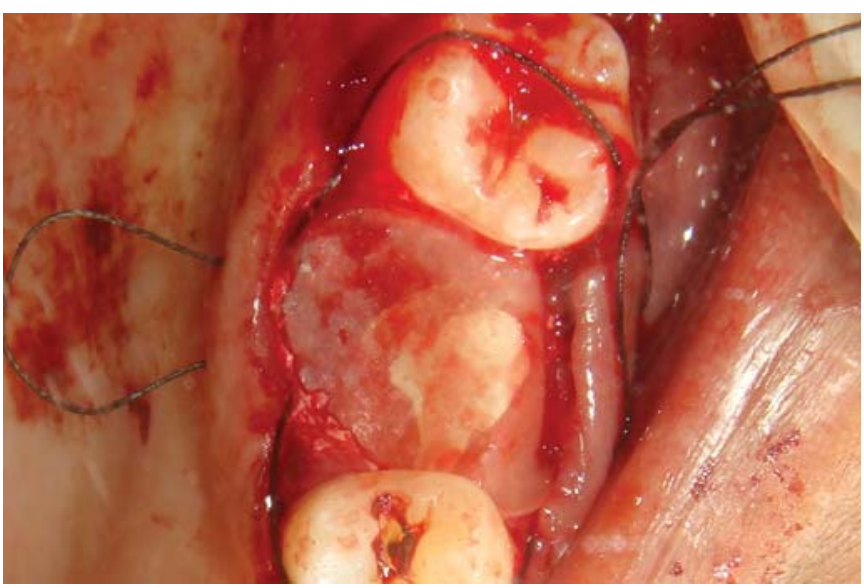

Fig. 16: Bioguide ${ }^{\mathrm{TM}}$ membrane placed

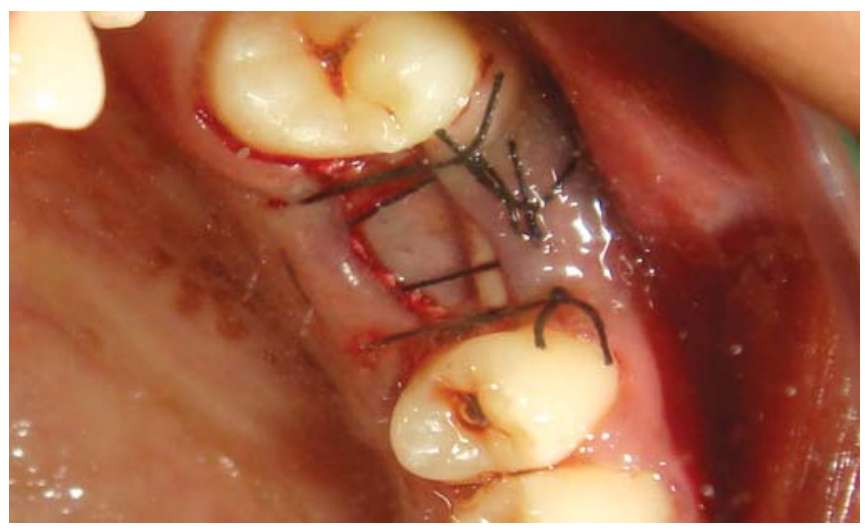

Fig. 17: Sutures placed

a chlorhexidine mouthrinse. The patients were asked to abstain from brushing on the surgical area for at least 1 week and they were recalled 1 week postoperatively during which sutures were removed and the operated area was evaluated for healing, infection and any signs of ulceration and necrosis which were tabulated separately in the chart provided.

Supportive periodontal therapy was provided every month in both test and control group. Patients were reevaluated at the end of 6th month.

\section{Statistical Analysis}

A student t-test for paired comparisons was used.

\section{RESULTS}

A total of 22 patients were recruited for the study. Seventeen patients returned regularly for the maintenance program and were included for the final analysis. Five patients were excluded from the study as they did not return after extraction of the first tooth or did not complete the follow-up period or needed further extractions adjacent to the sites initially included in the study.

Age and gender of patients: Out of 17 patients, nine patients were male and seven were female. The age of the patients ranged between 18 and 48 years with a mean age of 29.94 years (Tables 1 and 2).

Reason for extraction: Nine patients underwent extraction due to deep dental caries while the other eight patients had at least two teeth with circumferential bone loss nearing the apices due to periodontitis (LAP-3, GAP- 2, LP- 2, CGP-1) (Table 3).

\begin{tabular}{lcl}
\multicolumn{3}{c}{ Table 1: Gender distribution of patients studied } \\
\hline Gender & Number of patients & $\%$ \\
\hline Male & 9 & 52.9 \\
Female & 8 & 47.1 \\
\hline Total & 17 & 100.0 \\
\hline
\end{tabular}


Table 2: Age distribution of patients studied

\begin{tabular}{lcc}
\hline Age (in years) & Number of patients & $\%$ \\
\hline $18-20$ & 2 & 11.8 \\
$21-30$ & 8 & 47.1 \\
$31-40$ & 5 & 29.4 \\
$>40$ & 2 & 11.8 \\
\hline Total & 17 & 100.0 \\
\hline
\end{tabular}

Table 3: Diagnosis of patients studied

\begin{tabular}{lcc}
\hline Diagnosis & Number of patients & $\%$ \\
\hline Caries & 9 & 52.9 \\
LAP & 3 & 17.6 \\
GAP & 2 & 11.8 \\
LP & 2 & 11.8 \\
CGP & 1 & 5.9 \\
\hline Total & 17 & 100.0 \\
\hline
\end{tabular}

\section{Clinical Parameters}

Height of ridge: The distance from the occlusal stent to the crest of the alveolar ridge was measured at baseline as well as at 6 months for both the test and the control sites for the patients. It was found that the mean loss of height was $2.43 \mathrm{~mm}$ at the control sites and $1.45 \mathrm{~mm}$ at the test sites. The difference between the mean heights of the control and the test group also increased from $0.28 \mathrm{~mm}$ at baseline to $0.69 \mathrm{~mm}$ at 6 months. These results were found to be statistically significant (Table 4).

Width of the ridge: The width of the alveolar ridge was measured at baseline as well as at 6 months for both the test and the control site for the patients. The results showed that the mean loss of width at the control sites was $1.68 \mathrm{~mm}$ while the mean loss of width at the test site was $1.07 \mathrm{~mm}$.

Table 4: Comparative evaluation of height $(\mathrm{mm})$ in patients studied

\begin{tabular}{lllll}
\hline Height $(\mathrm{mm})$ & Control & Test & $\Delta$ & $p$-value \\
\hline Baseline & $8.63 \pm 1.73$ & $8.91 \pm 1.62$ & 0.28 & 0.290 \\
6 months & $11.06 \pm 2.01$ & $10.36 \pm 1.83$ & 0.69 & $0.009^{* *}$ \\
$\Delta$ & 2.43 & 1.45 & - & - \\
p-value & $<0.001^{* *}$ & $<0.001^{* *}$ & - & - \\
\hline
\end{tabular}

$\Delta$ : Difference (loss of height); ${ }^{*}$ Strongly significant $(p \leq 0.01)$
Table 5: Comparative evaluation of width $(\mathrm{mm})$ in patients studied

\begin{tabular}{lllll}
\hline Width $(\mathrm{mm})$ & Control & Test & $\Delta$ & $p$-value \\
\hline Baseline & $8.01 \pm 1.64$ & $8.33 \pm 1.32$ & 0.32 & 0.123 \\
6 months & $6.33 \pm 1.54$ & $7.26 \pm 1.10$ & 0.93 & $0.001^{\star *}$ \\
$\Delta$ & 1.68 & 1.07 & - & - \\
p-value & $<0.001^{\text {** }}$ & $<0.001^{* *}$ & - & - \\
\hline
\end{tabular}

$\Delta$ : Difference (loss of width); **Strongly significant $(\mathrm{p} \leq 0.01)$

Thus, the mean loss at the control sites was $0.61 \mathrm{~mm}$ more than at the test site. The mean difference between the width of the control and test sites increased from $0.32 \mathrm{~mm}$ at baseline to $0.93 \mathrm{~mm}$ at 6 months. These results were found to be statistically significant (Table 5).

\section{Radiographic Measurements}

Crestal bone level: The distance from the cementoenamel junction on the tooth adjacent to the extraction site and the radiographic crest of the bone was measured at baseline as well as at 6 months with the use of AutoCAD (Adobe version 2010) software. It was found that the crestal bone level reduced by $29 \mathrm{~mm}$ more at the teeth adjacent to the control sites than at the test sites. This was not found to be statistically significant.

Bone fill: The radiographic socket depth was measured by the use of AutoCAD (Adobe version 2010) as well as the corresponding bone fill that took place in each socket for both test and control sites. The depth of the socket as measured from the CEJ of the adjacent tooth till the base of socket was subtracted by the distance from the CEJ to the new crest of bone to arrive at the bone fill. The results showed a $0.98 \mathrm{~mm}$ of bone fill more on an average at the test site than at the control sites.

The bone fill \% was found to be $12.53 \%$ more at the test site than at the control site. These results were found to be statistically significant (Table 6).

All the individual results have been tabulated in the Master Chart.

\section{DISCUSSION}

Traditional methods of tooth extraction often result in loss of the labial plate of the alveolar bone. Atraumatic methods

Table 6: Comparative evaluation of bone fill \% in patients studied

\begin{tabular}{lllll}
\hline Bone fill\% & Control & Test & $\Delta$ & $p$-value \\
\hline Crestal bone level & $0.58 \pm 0.32$ & $0.87 \pm 1.60$ & 0.29 & 0.468 \\
Socket depth & $5.51 \pm 1.15$ & $6.01 \pm 1.02$ & 0.49 & $0.057^{\star}$ \\
Bone fill & $2.59 \pm 0.73$ & $3.58 \pm 0.84$ & 0.98 & $<0.001^{\star *}$ \\
Bone fill \% & $47.01 \pm 9.62$ & $59.54 \pm 9.61$ & 12.53 & $0.001^{\star *}$ \\
\hline
\end{tabular}

*Suggestive significance $(0.05<p<0.10) ;{ }^{*}$ Strongly significant $(p \leq 0.01)$ 
MASTER CHART

\begin{tabular}{|c|c|c|c|c|c|c|c|}
\hline \multirow[t]{2}{*}{ S. no. } & \multirow[t]{2}{*}{ Sex } & \multirow[t]{2}{*}{ Age } & \multirow[t]{2}{*}{ Diagnosis } & \multicolumn{2}{|c|}{ Control } & \multicolumn{2}{|c|}{ Test } \\
\hline & & & & Loss of height & Loss of width & Loss of height & Loss of width \\
\hline 1 & $M$ & 44 & LAP & 2.26 & 0.75 & 1.25 & 0.73 \\
\hline 2 & $\mathrm{~F}$ & 18 & Caries & 2.14 & 3.06 & 1.67 & 1.95 \\
\hline 3 & $\mathrm{~F}$ & 23 & Caries & 2.84 & 0.90 & 1.33 & 0.58 \\
\hline 4 & $M$ & 24 & Caries & 1.05 & 1.68 & 0.85 & 1.32 \\
\hline 5 & M & 26 & LP & 2.64 & 1.40 & 1.00 & 0.90 \\
\hline 6 & $M$ & 30 & GAP & 6.05 & 3.01 & 4.34 & 1.55 \\
\hline 7 & $\mathrm{~F}$ & 39 & LP & 2.27 & 1.36 & 1.58 & 0.94 \\
\hline 8 & M & 23 & Caries & 2.76 & 1.72 & 2.12 & 1.21 \\
\hline 9 & $\mathrm{~F}$ & 18 & Caries & 1.07 & 2.37 & 0.41 & 0.96 \\
\hline 10 & $M$ & 48 & CGP & 1.62 & 1.62 & 1.38 & 1.48 \\
\hline 11 & M & 26 & LAP & 2.23 & 1.29 & 1.48 & 0.92 \\
\hline 12 & $\mathrm{~F}$ & 34 & Caries & 2.32 & 1.22 & 1.14 & 0.71 \\
\hline 13 & M & 38 & Caries & 2.50 & 0.50 & 1.53 & 1.09 \\
\hline 14 & $\mathrm{~F}$ & 36 & Caries & 2.26 & 1.23 & 0.75 & 1.21 \\
\hline 15 & $\mathrm{~F}$ & 23 & Caries & 2.33 & 1.27 & 1.20 & 0.28 \\
\hline 16 & M & 28 & LAP & 2.38 & 2.68 & 0.94 & 1.13 \\
\hline 17 & $\mathrm{~F}$ & 31 & GAP & 2.66 & 2.60 & 1.76 & 1.33 \\
\hline
\end{tabular}

(Measurements are in $\mathrm{mm}$ )

\begin{tabular}{|c|c|c|c|c|c|c|c|c|c|c|c|}
\hline \multirow[t]{3}{*}{ S. no. } & \multirow[t]{3}{*}{ Sex } & \multirow[t]{3}{*}{ Age } & \multirow[t]{3}{*}{ Diagnosis } & \multicolumn{2}{|c|}{ Crest bone loss } & \multicolumn{6}{|c|}{ Bonefill\% } \\
\hline & & & & \multirow[t]{2}{*}{ Control } & \multirow[t]{2}{*}{ Test } & \multicolumn{3}{|c|}{ Control } & \multicolumn{3}{|c|}{ Test } \\
\hline & & & & & & Socket depth & Bone fill & Bone fill\% & $\begin{array}{l}\text { Socket } \\
\text { depth }\end{array}$ & $\begin{array}{l}\text { Bone } \\
\text { fill }\end{array}$ & $\begin{array}{l}\text { Bone } \\
\text { fill\% }\end{array}$ \\
\hline 1 & $M$ & 44 & LAP & 0.59 & 0.18 & 4.92 & 2.59 & 52.64 & 6.25 & 2.66 & 42.56 \\
\hline 2 & $\mathrm{~F}$ & 18 & Caries & 0.64 & 0.37 & 5.37 & 2.30 & 42.83 & 5.94 & 4.01 & 67.50 \\
\hline 3 & $\mathrm{~F}$ & 23 & Caries & 0.84 & 0.81 & 5.65 & 2.26 & 40.00 & 6.04 & 4.36 & 72.18 \\
\hline 4 & $M$ & 24 & Caries & 0.29 & 0.39 & 3.92 & 2.11 & 53.82 & 4.88 & 3.23 & 66.18 \\
\hline 5 & M & 26 & LP & 0.68 & 0.81 & 6.32 & 2.95 & 46.67 & 6.59 & 4.58 & 69.49 \\
\hline 6 & $M$ & 30 & GAP & 0.54 & 0.45 & 8.52 & 3.79 & 44.48 & 8.23 & 4.59 & 55.77 \\
\hline 7 & $\mathrm{~F}$ & 39 & LP & 0.15 & 0.82 & 5.53 & 1.90 & 34.35 & 5.31 & 2.49 & 46.89 \\
\hline 8 & M & 23 & Caries & 0.34 & 0.26 & 4.70 & 2.36 & 50.21 & 4.56 & 2.62 & 57.45 \\
\hline 9 & $\mathrm{~F}$ & 18 & Caries & 0.71 & 0.57 & 5.48 & 3.53 & 64.41 & 5.82 & 3.10 & 53.26 \\
\hline 10 & $\mathrm{M}$ & 48 & CGP & 0.01 & 0.01 & 4.09 & 1.07 & 26.16 & 7.78 & 3.92 & 50.38 \\
\hline 11 & M & 26 & LAP & 0.94 & 0.78 & 5.67 & 3.03 & 53.43 & 5.93 & 4.17 & 70.32 \\
\hline 12 & $\mathrm{~F}$ & 34 & Caries & 1.10 & 0.64 & 4.53 & 2.49 & 54.96 & 5.43 & 3.19 & 58.74 \\
\hline 13 & $M$ & 38 & Caries & 1.02 & 0.83 & 5.15 & 2.91 & 56.50 & 4.78 & 3.11 & 65.06 \\
\hline 14 & $\mathrm{~F}$ & 36 & Caries & 0.95 & 0.51 & 4.86 & 1.57 & 32.30 & 6.07 & 3.32 & 54.69 \\
\hline 15 & $\mathrm{~F}$ & 23 & Caries & 0.23 & 0.16 & 5.24 & 2.48 & 47.32 & 4.89 & 2.22 & 45.39 \\
\hline 16 & $M$ & 28 & LAP & 0.36 & 0.27 & 7.37 & 3.63 & 49.25 & 7.04 & 4.81 & 68.32 \\
\hline 17 & $\mathrm{~F}$ & 31 & GAP & 0.50 & 07 & 6.43 & 3.21 & 49.92 & 6.59 & 4.49 & 68.13 \\
\hline
\end{tabular}

(Measurements are in $\mathrm{mm}$ )

Study Design: A comparative evaluation clinical spilt-mouth study

of extraction focus on gently severing the periodontal attachment using microinstrumentation intending to preserve alveolar crestal height in all three dimensions.

Ridge preservation has been attempted with the use of various osseous graft materials, with or without the use of membranes as well as other materials, such as a polylactidepolyglycolide sponge or a collagen plug. Various graft materials, including autogenous bone, demineralized freezedried bone allograft, mineralized freeze-dried bone allograft, solvent-preserved mineralized bone allograft, bovine hydroxyapatite and alloplasts, have been evaluated in different studies for socket augmentation. The trauma of the extraction brings a cascade of events to fill the socket with bone. Grafting at the same time takes advantage of this phenomenon.

Sclar' in 1999 proposed the 'Bio-Col' socket augmentation technique. In his technique, bovine hydroxyapatite was used as graft material up to two-thirds of the socket, and the remaining socket was filled with the bioabsorbable collagen dressing (CollaPlug ${ }^{\mathrm{TM}}$ ).

This randomized, controlled clinical trial compared the healing potential of an unassisted extraction socket to one in which a bovine-derived xenograft was used in combination with a collagen plug and a collagen membrane according to the GTR principle, to preserve alveolar ridge dimensions and promote osseous healing of postextraction alveolar sockets. 
In the present investigation, full-thickness buccal and palatal/lingual mucoperiosteal flaps were raised to facilitate the placement of the barrier membranes over sound alveolar bone. It has been previously advocated that in full-thickness mucoperiosteal flaps, the bone-periosteum continuity is disrupted and a marginal bone resorption of approximately $1 \mathrm{~mm}$ should be anticipated. ${ }^{6}$

Based on this, it has been suggested that in cases of postextraction ridge preservation, flapless techniques should be utilized, because flap reflection may initiate further bone resorption in addition to that naturally occurring in the bundle bone of the alveolar socket as a result of postextraction healing.

The use of a naturally derived bovine hydroxyapatite osseous graft (Bio-Oss ${ }^{\mathrm{TM}}$ ) was decided upon for use in the current study due to it being well researched and having properties, such as a slow resorbing rate, superior handling characteristics, promotion of revascularization and clot stabilization and also optimal integration with the patients, own bone. ${ }^{7}$ Because of the nature of the extraction socket, the majority of bone graft may be lost, if no protection is provided. Therefore, the use of collagen wound dressing material was suggested not only to protect the graft material but also induce blood clot formation and stabilize the wound. ${ }^{8}$ A collagen dressing material is preferable due to its high biocompatibility and hemostatic ability that can enhance platelet aggregation and thus, facilitate clot formation and would stabilization. ${ }^{9}$ Collagen also has a high chemotactic function for fibroblasts. This might promote cell migration and primary wound coverage. ${ }^{10}$

Even though all efforts were taken to get maximum coverage of the membrane, complete coverage could not be attained in all of the cases. However, as shown in a study by Nam and Park in 2009, ${ }^{11}$ membrane exposure during the healing period did not affect the efficacy of ridge preservation procedures. Recent work by Araujo and Lindhe ${ }^{12}$ in a dog model showed using a subepithelial connective tissue graft taken by a window or envelope procedure from the palate may increase soft tissue coverage, but this did not result in increased bone fill. This finding suggests the use for a space filler to be placed in the socket or use of a membrane to maximize bone infill.

Uneventful healing was observed with both the test and control sites with none of the patients reporting back with pain, swelling, dry socket or other complications.

A decrease in the buccolingual dimension of the alveolar ridge was observed in both groups. This confirmed previous clinical and preclinical reports that postextraction healing is always characterized by osseous resorption and significant contour changes especially in the horizontal plane of the residual alveolar ridge.
The results of this study are in agreement with previous controlled studies where similar combinations of bone grafts or substitutes with resorbable barriers were successfully used for alveolar ridge preservation. ${ }^{13-15}$ However, complete preservation of the preextraction ridge dimensions should not be anticipated, even when alveolar ridge preservation techniques involving postextraction socket grafting are applied. These changes may be limited but not avoided.

In this study, the buccolingual dimension of the socket showed a mean dimension loss of $1.68 \mathrm{~mm}$ in the control group and $1.07 \mathrm{~mm}$ in the test group. The least amount of bone resorption following ridge preservation was seen in a patient who lost only $0.28 \mathrm{~mm}$ of ridge width. The maximum loss of ridge width was seen to be $1.93 \mathrm{~mm}$. The loss in the vertical measurement as measured from the occlusal stent showed a mean loss of $2.43 \mathrm{~mm}$ in the control group and $1.45 \mathrm{~mm}$ in the test group. The least amount of bone loss observed was $1.05 \mathrm{~mm}$ while the maximum bone loss seen in a patient was $6.05 \mathrm{~mm}$.

Similar postextraction alveolar ridge resorption was observed in previous randomized, controlled clinical trials where extraction sockets were treated with either a porcine xenograft and a collagen barrier or freeze-dried bone and a collagen membrane and compared with the healing of 'empty' untreated extraction sockets. ${ }^{14}$

Standardized periapical X-rays were taken at baseline and after 6 months. The levels of the alveolar bone crest from CEJ of the adjacent tooth till the alveolar crest were recorded. In the present study, film type, time of exposure, film processing and radiographic equipment were fully standardized for all the radiographs taken. On the other hand, it should be emphasized that some degree of magnification is inevitable despite the fact that the intraoral radiographs were standardized. This magnification could be attributed to possible tooth migration or occlusal changes that occurred during the 6 months study period. The difference in crestal bone levels between the control and test group was about $0.29 \mathrm{~mm}$. This was not found to be statistically significant. The mean bone fill was found to be $0.98 \mathrm{~mm}$ more in the test sites when compared to the control groups. Also, the bone fill \% was found to be $12.53 \%$ more in the test groups. These results were statistically significant. A similar result was reported in a study by Mardas et al on 27 patients. ${ }^{15}$

In the present study, no effort was made to select a predetermined type of socket as in some previous studies. ${ }^{16}$ The extraction sockets in this study presented with different soft tissue quantities, qualities and gingival tissue biotypes as well as with different anatomical and dimensional characteristics of the hard tissue compartment. Obviously, some of these characteristics, together with several other 
factors (e.g. reason for extraction, tooth location, etc.) may influence the final outcome of any socket preservation procedure and may be important in making the decision of whether or not a ridge preservation technique is indicated.

The results of this study indicate that ridge preservation approach (using xenograft in combination with a collagen membrane and CollaPlug ${ }^{\mathrm{TM}}$ ) significantly limited the reabsorption of hard tissue ridge after tooth extraction compared to extraction alone.

\section{CONCLUSION}

Regardless of the reasons for socket preservation, clinicians must be aware that sufficient alveolar bone volume and favorable architecture of the alveolar ridge are essential to achieve ideal functional and esthetic prosthetic reconstruction following implant therapy.

The results of this study revealed that ridge preservation procedure carried out immediately after extraction significantly reduced the alveolar bone resorption following tooth extraction when compared to extraction alone. The patient undergoing this procedure would be benefited by the presence of a ridge form that would allow for better esthetics, contour of fixed and removable prosthesis or even implant placement if necessary. The patient would also be spared the additional expense and trauma of ridge augmentation procedures to correct ridge defects.

\section{REFERENCES}

1. Nemcovsky CE, Serfaty V. Alveolar ridge preservation following extraction of maxillary anterior teeth. Report on 23 consecutive cases. J Periodontol 1996;67:390-95.

2. Luczyszyn SM, Papalexiou V, Novaes AB Jr, Grisi MF, Souza SL, Taba M Jr. Acellular dermal matrix and hydroxyapatite in prevention of ridge deformities after tooth extraction. Implant Dent 2005;14:176-84.

3. Wang HL, Kiyonobu K, Neiva RF. Socket augmentation: Rationale and technique. Implant Dent 2004;13:286-96.

4. Misch CE, Dietsh-Misch F, Misch CM. A modified socket seal surgery with composite graft approach. J Oral Implantol 1999;25:244-50.

5. Qian JJ, Bhatnagar RS. Enhanced cell attachment to an organic bone mineral in the presence of a synthetic peptide related to collagen. J Biomed Mater Res 1996;31:545-54.

6. Moghaddas H, Stahl SS. Alveolar bone remodeling following osseous surgery. A clinical study. J Periodontol 1980;51: 376-81.

7. Mendonça TA, Conz MB, Barros TC, de Sena LA, Soares Gde A, Granjeiro JM, et al. Physicochemical characterization of two deproteinized bovine xenografts. Braz Oral Res 2008;22(1): 5-10.

8. Wang HL, Kiyonobu K, Neiva RF. Socket augmentation: Rationale and technique. Implant Dent 2004;13:286-96.

9. Sableman E. Biology, biotechnology and biocompatibility of collagen. In: Williams DF (Ed). Biocompatibility of Tissue Analogs.Boca Raton, FL: CRC Press 1985:27.

10. Postlethwaite AE, Seyer JM, Kang AH. Chemotactic attraction of human fibroblasts to type I, II and III collagens and collagenderived peptides. Proc Natl Acad Sci USA 1978;75:871-75.

11. Nam WH, Park JY. The influence of membrane exposure on post-extraction dimensional change following ridge preservation technique. J Korean Acad Periodontol Sep 2009;39(3):367-74.

12. Atwood DA, Coy WA. Clinical, cephalometric and densitometric study of reduction of residual ridges. J Prosthet Dent 1971;26:280-95.

13. Vance GS, Greenwell H, Miller RL, Hill M, Johnston H, Scheetz JP. Comparison of an allograft in an experimental putty carrier and a bovine-derived xenograft used in ridge preservation: A clinical and histologic study in humans. The International Journal Oral \& Maxillofacial Implants 2004;19:491-97.

14. Barone A, Aldini NN, Fini M, Giardino R, Calvo Guirado JL, Covani U. Xenograft versus extraction alone for ridge preservation after tooth removal: A clinical and histomorphometric study. J Periodontol 2008;79:1370-77.

15. Mardas N, Kostopoulos L, Stavropoulos A, Karring T. Osteogenesis by guided tissue regeneration and demineralised bone matrix. J Clin Periodontol 2003;30:176-83.

16. Juodzbalys G, Sakavicius D, Wang HL. Classification of extraction sockets based upon soft and hard tissue components. J Periodontol 2008;79:413-24.

\section{ABOUT THE AUTHORS}

\section{Dhruv Gupta}

Postgraduate Student, Department of Periodontics, The Oxford Dental College, Hospital and Research Centre, Bengaluru, Karnataka, India

\section{Gayatri Gundannavar (Corresponding Author)}

Reader, Department of Periodontics, The Oxford Dental College Hospital and Research Centre, Bengaluru, Karnataka, India e-mail: gayatrigundannavar@ yahoo.com

\section{Dwarakanath Doraiswamy Chinni}

Professor, Department of Periodontics, The Oxford Dental College Hospital and Research Centre, Bengaluru, Karnataka, India

\section{Ramesh Vishwanath Alampalli}

Professor, Department of Periodontics, The Oxford Dental College Hospital and Research Centre, Bengaluru, Karnataka, India 